\title{
Persistent negative illness perceptions despite long-term biochemical control of acromegaly: novel application of the drawing test
}

\author{
Jitske Tiemensma ${ }^{1,2}$, Alberto M Pereira ${ }^{2}$, Johannes A Romijn ${ }^{3}$, \\ Elizabeth Broadbent ${ }^{4}$, Nienke R Biermasz ${ }^{2}$ and Adrian A Kaptein ${ }^{5}$ \\ ${ }^{1}$ Psychological Science, University of California Merced, 5200 North Lake Road, Merced, California 95343, USA, \\ ${ }^{2}$ Department of Endocrinology \& Metabolism and Center for Endocrine Tumors Leiden (CETL), Leiden University \\ Medical Center, Leiden, The Netherlands, ${ }^{3}$ Department of Medicine, Academic Medical Center, University of \\ Amsterdam, Amsterdam, The Netherlands, ${ }^{4}$ Department of Psychological Medicine, University of Auckland, \\ Auckland, New Zealand and ${ }^{5}$ Department of Medical Psychology, Leiden University Medical Center, Leiden, \\ The Netherlands
}

\author{
Correspondence \\ should be addressed to \\ J Tiemensma \\ Email \\ jtiemensma@ucmerced.edu
}

\section{Abstract}

Context and objective: Patients with acromegaly have persistent complaints despite long-term biochemical control. Drawings can be used to assess patients' perceptions about their disease. We aimed to explore the utility of the drawing test and its relation to illness perceptions and quality of life $(\mathrm{Q} O L)$ in patients after long-term remission of acromegaly.

Design: A cross-sectional study was conducted to evaluate the utility of the drawing test.

Methods: A total of 50 patients after long-term remission (mean \pm s.E.M., $16 \pm 1.2$ years) of acromegaly were included in this study. Patients completed the drawing test (two retrospective drawings of their body perception before acromegaly and during the active phase of acromegaly, and one drawing on the current condition after long-term remission), Illness Perception Questionnaire-Revised, Physical Symptom Checklist, EuroQoL-5D, and AcroQoL.

Results: Patients perceived a dramatic change in body size during the active state of the disease compared with the healthy state before the awareness of acromegaly. Patients reported that their body did not completely return to the original proportions after long-term remission. In addition, larger drawings indicated more negative consequences $(P<0.05)$, a higher score on emotional representations $(P<0.05)$, and more perceived symptoms that were attributed to acromegaly $(P<0.01)$. Larger drawings also indicated more impaired QoL, especially disease-specific QoL (all $P<0.05)$. Conclusion: There are strong correlations among the drawing test, illness perceptions, and QoL. The drawing test appears to be a novel and relatively easy tool to assess the perception of patients after long-term remission of acromegaly. The assessment of drawings may enable health care providers to appreciate the perceptions of patients with long-term remission of acromegaly, and enable discussion of symptoms and remission.

\section{Introduction}

Acromegaly is a rare condition that is associated with typical signs and symptoms caused by an excess of both growth hormone $(\mathrm{GH})$ and insulin-like growth factor 1 (IGF1). Even after successful treatment, many of the systemic changes caused by GH and IGF1 are not completely reversed (1). In addition, impaired quality of life (QoL) has been reported despite long-term cure (2).
Impaired QoL may originate from persisting limitations due to previous excessive GH and IGF1 overexposure, but could also be due to psychological impairments. Our research group has recently explored illness perceptions as a possible contributor to this observed impaired QoL. Indeed, patients in long-term remission of acromegaly reported negative illness perceptions and ineffective (c) 2015 European Society of Endocrinology Printed in Great Britain
Published by Bioscientifica Ltd. 
coping strategies, and those negative illness perceptions were associated with impaired QoL $(3,4)$. These findings were in agreement with the common sense model (CSM) of self-regulation (5). Specifically, the CSM explains as to how patients generate cognitive representations of their illness and emotional reactions to their illness by integrating internal and external stimulus information with their pre-existing illness theory (6). Leventhal et al. (5) states that patients cluster their cognitive representations or ideas about the illness around five components: i) identity: the label that is used by the individual to describe the condition and the associated symptoms; ii) cause: ideas about the cause of the condition; iii) timeline: expectations about the likely duration of the condition; iv) consequences: the physical, psychological, and social consequences of the condition; and v) cure/control: the extent to which the condition is amenable to cure and/or control. These components form the illness representations, which determine the coping procedures of the patient (7). Ultimately, both illness perceptions and coping strategies inform and predict outcome, such as QoL.

The drawing test is a novel and easy method to assess the perceptions that patients have about their disease. In the drawing test, patients are asked to draw their body during the various stages of their condition retrospectively: i) before disease, ii) during the active state of disease, and iii) currently after treatment. It is presumed that drawings can illustrate patients' notions in a more uncensored, concrete, and specific way than words (i.e., questionnaires or structured interviews) $(8,9)$. Furthermore, it is believed that drawings can play an important role in identifying idiosyncratic beliefs that are crucial for medication adherence, self-management behavior, and QoL (10).

The drawing test has successfully been used in patients after long-term remission of Cushing's syndrome (11), and other chronic conditions such as myocardial infarction (10), heart failure (9), headache (12), postpartum hemorrhage (13), vestibular schwannoma (14), and systemic lupus erythematosus (15). Drawings appeared to reflect a new dimension of the psychological impact of long-term remission of Cushing's syndrome. Drawings and scores on an Illness Perception Questionnaire (IPQ) showed marginal correlations (11). The other studies using the drawing test in non-endocrine conditions showed that drawings illustrate the functional and psychological status of the patient.

There are no previous studies that utilized the drawing test in patients after long-term remission of acromegaly. Therefore, the aim of this study was to explore the utility of the drawing test in patients after long-term remission of acromegaly. Based on the results in our previous study in Cushing's syndrome, we hypothesized that drawings might reflect a new dimension of the psychological impact of long-term remission of acromegaly.

\section{Patients and methods}

\section{Design}

We performed a cross-sectional study in which patients in long-term remission after treatment of acromegaly were invited to draw three images of their body (see below). Inclusion criteria were age $>18$ years and prolonged remission of acromegaly (i.e., $\geq 1$ year). The protocol was approved by the Institutional Medical Ethics Committee of the Leiden University Medical Center.

\section{Patients}

We performed a clinical chart review of 156 patients with acromegaly. All patients were in biochemical remission at the time of the current study for at least 1 year. We invited these patients to participate in the current study. Of them, 75 patients (48\%) refused to participate for several reasons including lack of time, old age, and/or debilitating disease. Although 81 patients (52\%) completed the questionnaires, only 50 patients $(32 \%)$ made drawings in addition to completion of the questionnaires. Therefore, 50 patients were included in the current study.

The diagnosis of acromegaly had been established by clinical signs and symptoms and by biochemical tests, including insufficient suppression of GH during glucose tolerance test and increased IGF1 levels for age. Biochemical control of acromegaly was defined by normal serum IGF1 levels for age and serum GH levels below $1.9 \mu \mathrm{g} / \mathrm{l}$ for all patients and, in patients without somatostatin analog treatment, also by normal suppression of GH levels $(<0.38 \mu \mathrm{g} / \mathrm{l})$ during the glucose tolerance test (16). Remission was confirmed by repeating these tests at yearly intervals. Pituitary function was monitored and pituitary hormone replacement was prescribed dependent on the results of the yearly evaluation of pituitary functions. Hydrocortisone was prescribed $(20 \mathrm{mg} /$ day divided into two to three dosages) in case of corticotrope insufficiency, documented by the insulin tolerance test (ITT) or corticotropin-releasing hormone test. Evaluation of GH deficiency was performed by ITT or GH-releasing hormone-arginine test, only in patients under the age of 70 years and only after at least 2 years of remission. Somatotrope insufficiency was treated by rhGH 
replacement, aiming at IGF1 concentrations in the normal range for age. Patients were treated with rhGH from 2005 onwards during a controlled trial of rhGH replacement (17). In addition, free thyroxine and, in male patients, testosterone levels were assessed. If results were below the lower limit of the respective reference ranges, substitution with levothyroxine and/or testosterone was prescribed. In the case of amenorrhea and low estradiol levels in premenopausal women, estrogen replacement was provided.

\section{Methods}

Patients were asked to make three drawings and complete questionnaires on QoL and illness perceptions at home and return these in a prepaid envelope.

Drawing test - Patients were given three sheets of paper that included the following instructions: 'please draw a picture of what you think your body looked like before you developed acromegaly (drawing 1), a picture of what you think your body looked like when acromegaly was diagnosed, before treatment (drawing 2), and another picture of what you think your body looks like currently, after treatment for acromegaly (drawing 3). We are not interested in your drawing ability - a simple sketch is fine. We are interested in what you think has happened to your body. Could you describe what you drew at the bottom of each drawing?'.

IPQ-Revised • The IPQ-Revised (IPQ-R) (18) was used to measure current cognitive and emotional perceptions about acromegaly. This questionnaire was developed to assess the components of the illness representation of Leventhal's self-regulatory model and has been used to study illness perceptions in chronic conditions. Recently, we have reported IPQ-R data in the same cohort of patients after long-term remission of acromegaly, and a detailed description of the questionnaire can be found in Tiemensma et al. (4).

In short, the IPQ-R is divided into three sections. The first part consists of the illness identity dimension, with a list of 14 commonly occurring symptoms. Patients are asked to rate whether or not they experienced the symptoms, and if they believe the symptom to be related to acromegaly (yes/no). The summed yes-rated items of the disease-related symptoms are used in the analysis. The second part of the questionnaire, assessing illness perception dimensions, consists of 38 statements concerning views on the illness, scored on a five-point Likert scale (from strongly disagree to strongly agree). The questions are transformed to seven dimensions: i) timeline acute/ chronic: beliefs about the chronic nature of the condition; ii) timeline cyclical: beliefs regarding the cyclical nature of the condition; iii) consequences: negative consequences of the disease; iv) emotional representations: negative beliefs about how the illness affects one's emotional wellbeing; v) personal control: perceived personal controllability of the disease; vi) treatment control: perceived treatment controllability of the disease; and vii) illness coherence: personal understanding of the disease. A higher score indicates a stronger belief in that particular dimension. The third and final part of the questionnaire entails causal attributions. However, this section was not used in this study.

QoL questionnaires $\downarrow$ Physical Symptom Checklist $\bullet$ This is a checklist of 55 physical symptoms that are mentioned in the DSM-III classification (19). The symptoms cover most organ systems. There are 11 general/neurological items, ten autonomic items, eight musculoskeletal/pain items, 13 gastrointestinal items, five genital items, and four items about feeling hot/cold. The presence of symptoms is rated on a severity scale from 0 to 3 . We excluded the sexspecific items $(n=4)$ from the analyses to rule out bias by sex. The total symptom score ranges from 0 to 153. A higher score indicates more (severe) physical symptoms in the preceding week (20).

EuroQoL-5D - This QoL questionnaire assesses the current health status reflected in five health dimensions: mobility, self-care, usual activities, pain/discomfort, and anxiety/ depression. Scores are expressed on a one to three scale per dimension, with a higher score indicating a worse QoL. The questionnaire also includes a visual analog scale (VAS), which comprises a standard vertical $20 \mathrm{~cm}$ scale (similar to a thermometer) for recording an individual's rating for their current health-related QoL state (21). The VAS score ranges from 0 to 100 , with higher scores indicating a better QoL.

AcroQoL - This is a disease-specific QoL questionnaire designed to assess QoL in acromegaly (22). The AcroQoL consists of 22 questions on a five-point Likert scale. The response choices are divided into frequency of occurrence (ranging from 'always' to 'never') and degree of agreement with the items (ranging from 'completely agree' to 'completely disagree'). The total score ranges from 0 to 100, with a lower score indicating a greater impact on health-related QoL. Furthermore, three subscales can be calculated: physical complaints (score ranges from 0 to 100), 
Table 1 Clinical characteristics. Data are expressed as mean (s.D.) or $n(\%)$ unless otherwise stated.

\begin{tabular}{|c|c|}
\hline & $\begin{array}{l}\text { Patients in remission } \\
\text { of acromegaly }(n=50)\end{array}$ \\
\hline Sex (male/female) & $32 / 18$ \\
\hline Age (years) & 59.28 (11.9) \\
\hline \multirow{3}{*}{ Education level, $n(\%)$} & Low: $10(20 \%)$ \\
\hline & Medium: $16(32 \%)$ \\
\hline & High: $24(48 \%)$ \\
\hline Transsphenoidal surgery, $n(\%)$ & $46(92 \%)$ \\
\hline Somatostatin analog therapy, $n(\%)$ & $11(22 \%)$ \\
\hline Pegvisomant therapy, $n(\%)$ & $5(10 \%)$ \\
\hline Dopamine agonist therapy, $n(\%)$ & $4(8 \%)$ \\
\hline Postoperative radiotherapy, $n(\%)$ & $13(26 \%)$ \\
\hline Duration of follow-up (years) & $15.8(8.5)$ \\
\hline \multirow[t]{6}{*}{ Hypopituitarism, $n(\%)$} & Any axis: $19(38 \%)$ \\
\hline & GH: $8(16 \%)$ \\
\hline & ACTH: $13(26 \%)$ \\
\hline & LH/FSH: $10(20 \%)$ \\
\hline & TSH: $12(24 \%)$ \\
\hline & ADH: $1(2 \%)$ \\
\hline
\end{tabular}

appearance issues (score ranges from 0 to 100), and personal relation issues (score ranges from 0 to 100). A lower score on the subscales indicates a greater impact on QoL.

\section{Statistical analysis}

The drawings were scanned and imported into the freely available NIH ImageJ Software (23). The outside parameters of the drawing, head, right hand, and right foot were traced and computed. In addition, two independent observers scored the symptoms shown in the drawings. Subsequently, $\kappa$ scores were calculated for each symptom. When the $\kappa$ was $<0.7$, consensus was reached between the raters by reanalyzing the drawings together.

Data were analyzed using PASW Statistics version 17.0.2 (SPSS, Inc.). All data are expressed as mean \pm s.D.s, unless stated otherwise. The primary analysis comprised the association between the drawings and QoL and illness perceptions using Pearson's correlation coefficients. Only drawing 3 (current state) and the delta of drawing 3 vs drawing 2 (i.e., the perceived change) were used when analyzing possible associations between the drawings and various questionnaires.

To check the normality of the data, the KolmogorovSmirnov test was used in addition to histograms and box plots. Extreme outliers were removed from the dataset based on the box plots. Spearman's $\rho$ correlation coefficient was used for data that were not normally distributed. $\chi^{2}$ was used in case of categorical data. In addition, deltas were calculated based on the percentage of increase or decrease with the formula (( (last measurement/first measurement) -1$) \times 100$ ).

In view of the exploratory nature of this investigation, adjustment of the level of significance for multiple testing was not performed and the level of significance was set at $P \leq 0.05$.

\section{Results}

\section{Sociodemographic and clinical characteristics}

The sociodemographic and clinical characteristics are given in Table 1. At the time of the current study, all patients were in long-term biochemical remission, with a follow-up duration of $15.8 \pm 8.5$ years (range $2-35$ years).

\section{Size and characteristics of drawings}

Both Tables 2 and 3 list the drawing characteristics. Table 2 shows the size of drawings in pixels. Figure 1 shows the relative changes in size between the drawings. The baseline in this figure is drawing 1 (at 0\%). Drawing 2 (active state) was significantly higher and wider than drawing 1 (healthy state before disease). The head, hand, and foot in drawing 2 were all significantly wider than those in drawing 1 . In addition, drawing 3 (current state) showed a wider head, hand, and foot compared with drawing 1 (healthy state), and was wider and higher in general compared with drawing 1 . Finally, the size of the head and hand in drawing 2 (active state) was significantly wider than the drawn head and hand in drawing 3 (current state). Figure 2 shows examples of the drawings made by patients in long-term remission after acromegaly.

Table 3 lists the symptoms that were observed in the drawings. A large portion of the patients drew their whole body in all drawings. It should be noted that 10 (20\%) patients did not draw drawing 3; most of those patients

Table 2 Drawing characteristics: size of drawings in pixels. Data are expressed as mean (s.D.).

\begin{tabular}{|c|c|c|c|}
\hline & Drawing 1 & Drawing 2 & Drawing 3 \\
\hline $\begin{array}{l}\text { Height of } \\
\text { drawing }\end{array}$ & 1796.92 (599.9) & $2068.23(835.5)$ & $1876.87(635.5)$ \\
\hline $\begin{array}{l}\text { Width of } \\
\text { drawing }\end{array}$ & $1095.02(501.3)$ & 1568.06 (831.6) & $1295.85(563.4)$ \\
\hline Head (width) & 341.36 (167.1) & 435.05 (200.7) & 375.17 (164.2) \\
\hline Hand (width) & 124.39 (61.3) & $233.80(108.8)$ & $170.06(82.6)$ \\
\hline Foot (width) & $198.61(88.4)$ & $303.15(152.8)$ & 249.34 (111.7) \\
\hline
\end{tabular}


Table 3 Drawing characteristics: symptoms. Data are expressed as percentage of sample.

\begin{tabular}{|c|c|c|c|}
\hline & Drawing 1 & Drawing 2 & Drawing 3 \\
\hline \multirow[t]{5}{*}{ What was drawn } & Whole body: 80.0 & Whole body: 70.0 & Whole body: 64.0 \\
\hline & Head only: 8.0 & Head only: 6.0 & Head only: 2.0 \\
\hline & Loose parts: 8.0 & Loose parts: 14.0 & Loose parts: 10.0 \\
\hline & Other: 2.0 & Other: 6.0 & Other: 4.0 \\
\hline & Writing only: 2.0 & Writing only: 4.0 & Writing only: 20.0 \\
\hline \multicolumn{4}{|l|}{ Emotion } \\
\hline Negative & 0.0 & 8.3 & 5.0 \\
\hline Positive & 32.7 & 16.7 & 30.0 \\
\hline Pain & 0.0 & 2.1 & 2.5 \\
\hline \multicolumn{4}{|c|}{ Body parts were drawn bigger/hoarser compared with D1 } \\
\hline Head in general & NA & 66.7 & 47.5 \\
\hline Lips & NA & 20.8 & 10.0 \\
\hline Nose & NA & 41.7 & 20.0 \\
\hline Chin & NA & 56.4 & 32.5 \\
\hline Ears & NA & 16.7 & 2.5 \\
\hline Forehead & NA & 27.1 & 2.5 \\
\hline Tongue & NA & 2.1 & 0.0 \\
\hline Hands & NA & 68.8 & 57.5 \\
\hline Feet & NA & 52.1 & 50.0 \\
\hline Whole body & NA & 68.8 & 57.5 \\
\hline
\end{tabular}

NA, not applicable.

$(n=7,70 \%)$ wrote a note saying that the researchers should look at drawing 2 (i.e., no change), two patients (20\%) wrote a note saying that the researchers should look at drawing 1 , and one patient (10\%) left drawing 3 blank without explanation.

Furthermore, there was no negative emotion present in drawing 1, whereas some patients drew negative emotions in drawings 2 and 3 . The opposite was true for positive emotion: positive emotion was present in drawing 1 and to a much lesser extent in drawing 2. Drawing 3 showed comparable numbers of positive emotion. Multiple body parts were drawn bigger or hoarser in drawings 2 and 3 compared with drawing 1 . Specifically, over $20 \%$ of all patients drew bigger lips, nose, chin, forehead, hands and feet, and a bigger head and body in general in drawing 2 compared with drawing 1 . A smaller percentage of patients also drew enlarged ears and tongue in drawing 2. In drawing 3, over $20 \%$ of all patients drew enlarged nose, chin, hands and feet, and a bigger head and body in general compared with drawing 1. A smaller percentage of patients also drew larger lips, ears, and forehead in drawing 3 compared with drawing 1 .

The symptoms that were drawn showed the same pattern as the size of the drawings: both drawing 2 (active state) and drawing 3 (current state) are bigger and show more symptoms of acromegaly compared with drawing 1 (healthy state), with drawing 2 being more affected than drawing 3.

\section{Association between drawings and illness perceptions}

Patients' scores on the IPQ-R are given in Table 4. Illness identity was positively associated with the width of drawing $3(R=0.607, P<0.01)$ as well as with the width of the hand in drawing $3(R=0.510, P<0.01)$, meaning that wider drawings and larger hands are associated with more perceived symptoms that are attributed to acromegaly. Cyclical timeline was positively correlated with the width of drawing $3(R=0.449, P<0.01)$, indicating that a wider drawing is related to a cyclical timeline of

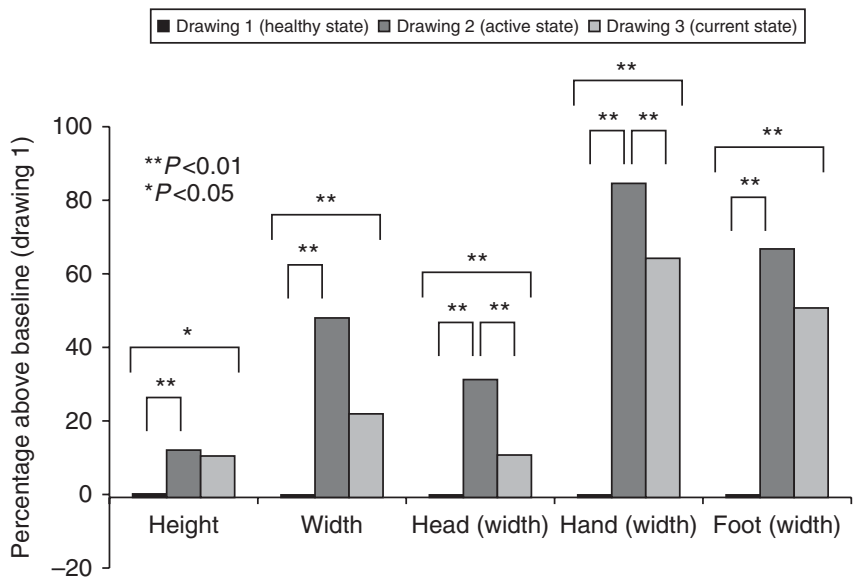

Figure 1

Changes in size of the drawings (drawing 1: baseline, $0 \%$ ). 
A

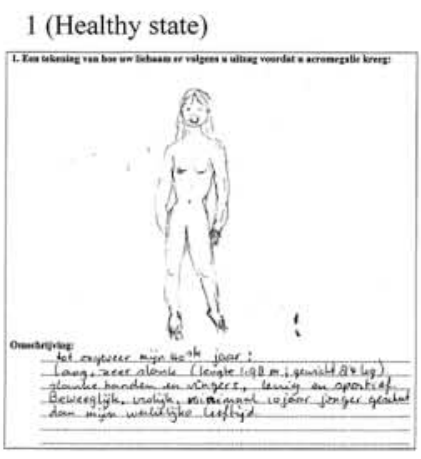

\section{B}

1 (Healthy state)

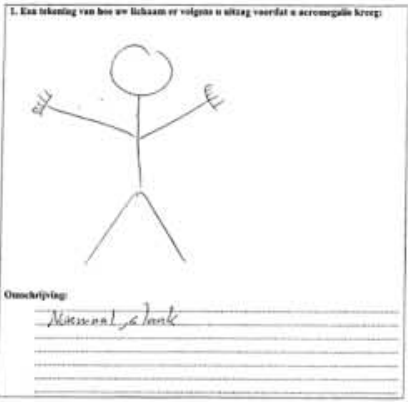

C

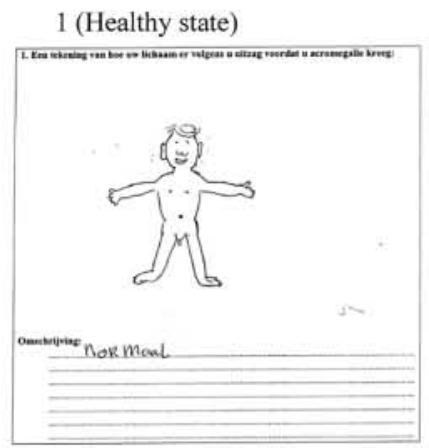

D

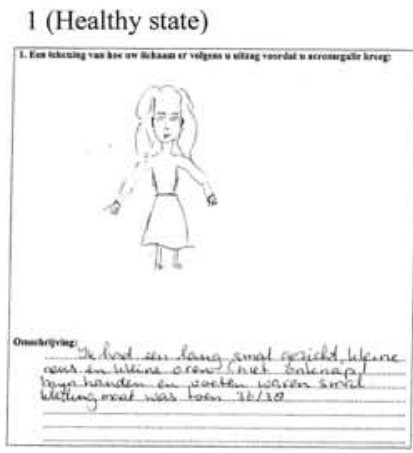

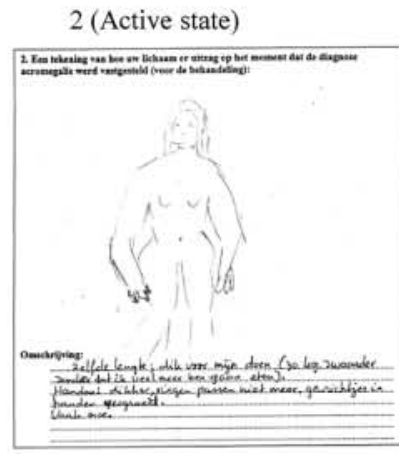

3 (Current state)

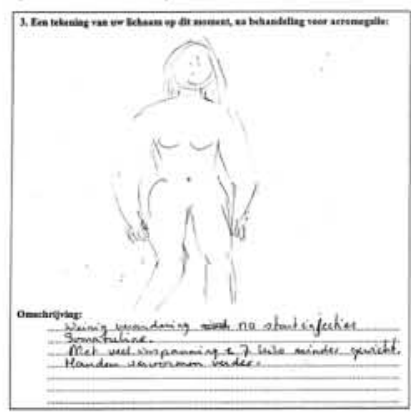

3 (Current state)
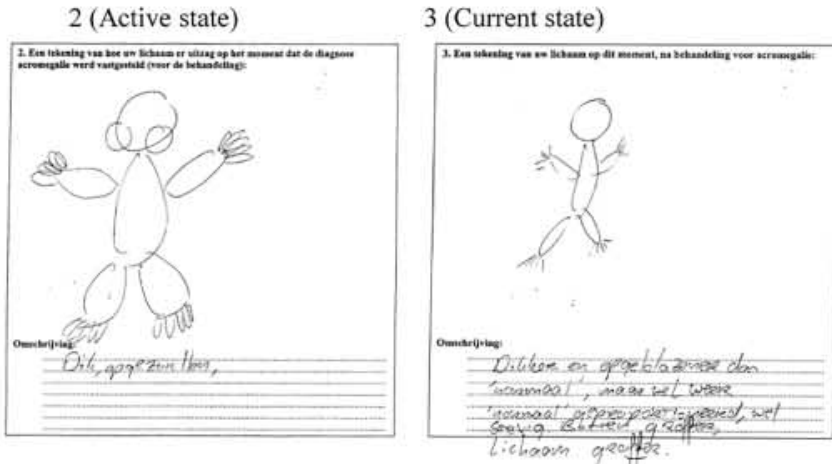

3 (Current state)
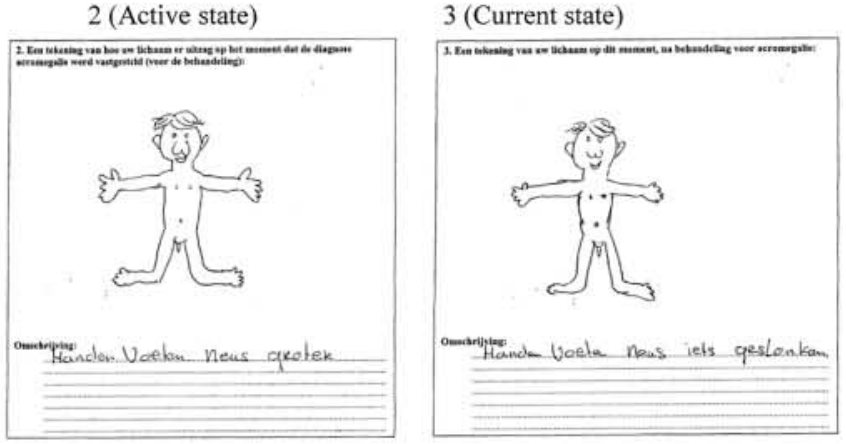

2 (Active state)

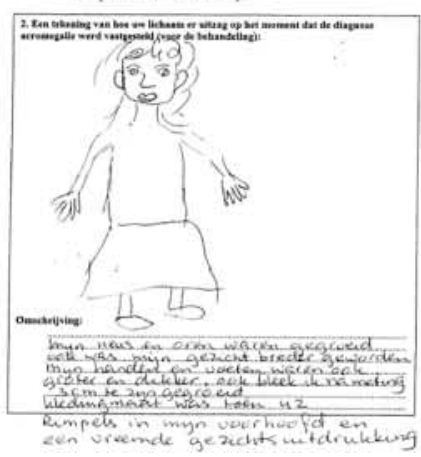

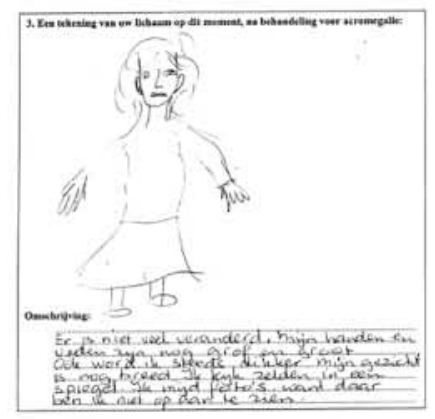

3 (Current state)

Figure 2 (legend continued) 
E

1 (Healthy state)

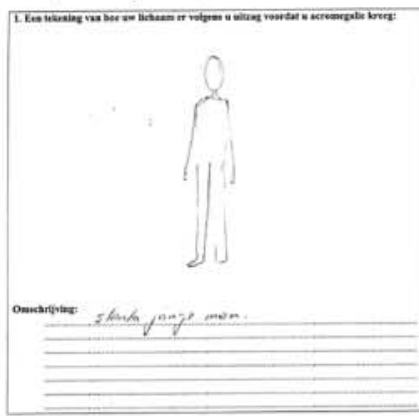

F

1 (Healthy state)

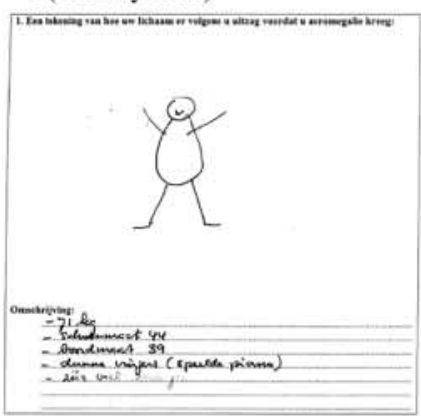

G

1 (Healthy state)

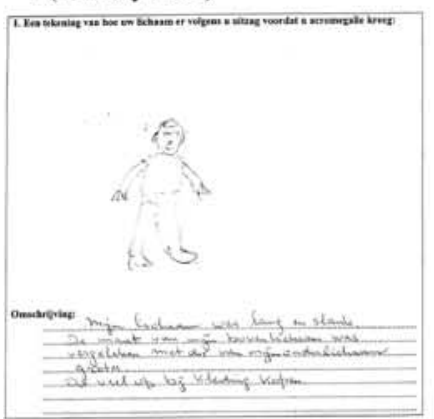

$\mathrm{H}$

1 (Healthy state)

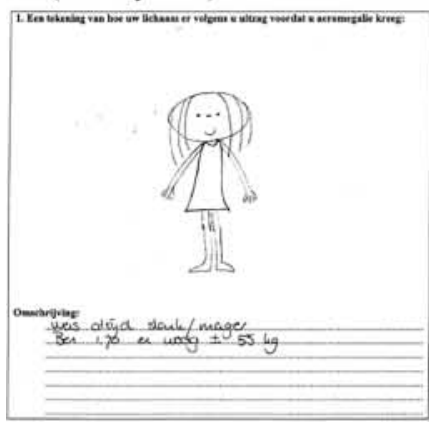

2 (Active state)

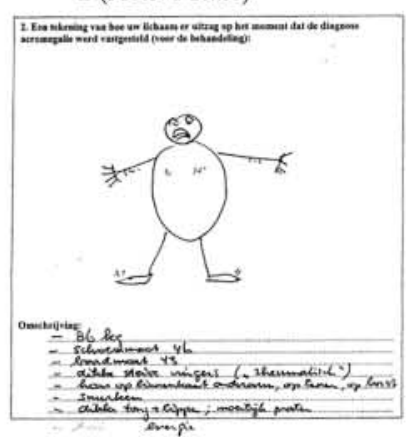

2 (Active state)

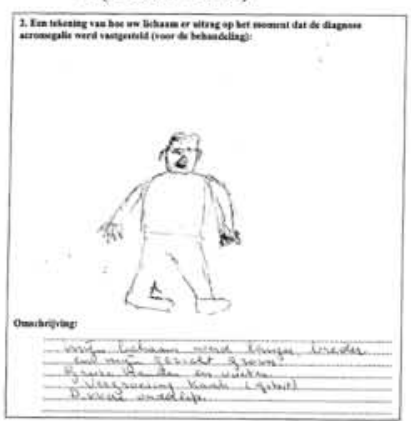

2 (Active state)

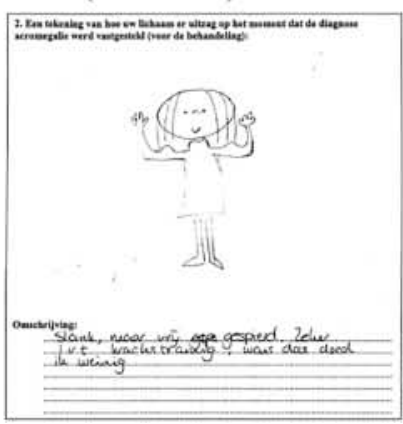

3 (Current state)

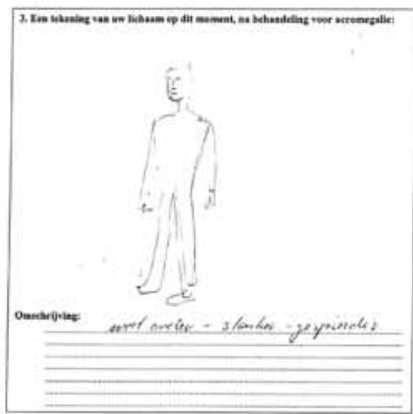

3 (Current state)

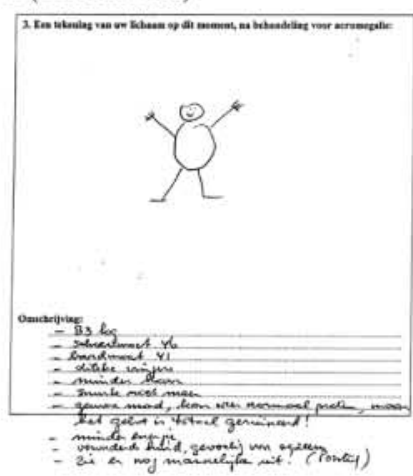

3 (Current state)

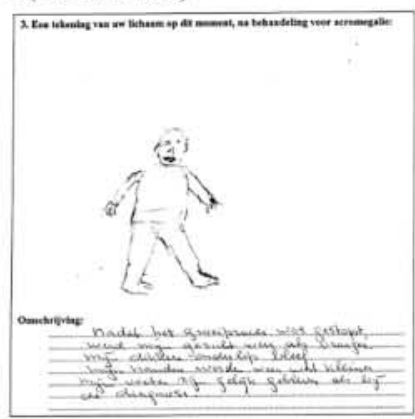

3 (Current state)

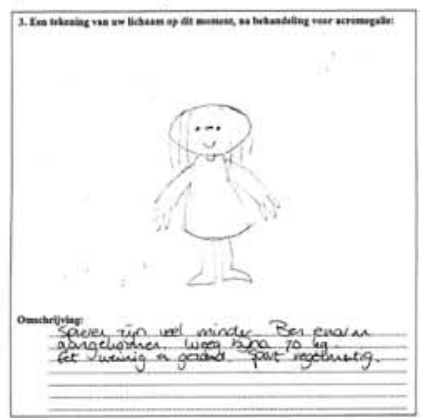


acromegaly. Perceived negative consequences of acromegaly were positively associated with the height and width of drawing 3 ( $R=0.377, P<0.05$ and $R=0.479, P<0.01$ respectively), as well as with the width of the head $(R=0.390, P<0.05)$ and hand $(R=0.392, P<0.05)$ in drawing 3 . This indicates that larger drawings (as well as larger body parts in those drawings) are associated with more negative consequences. Furthermore, emotional representations were positively correlated with the width of the head and hand in drawing $3(R=0.342, P<0.05$ and $R=0.366, P<0.05$ respectively). This means that a wider hand and head are associated with stronger emotional representations.

\section{Association between drawings and QoL}

The scores on the QoL questionnaires are listed in Table 4. The Physical Symptom Checklist (PSC) was positively associated with the width of drawing $3(R=0.400$, $P<0.05$ ), indicating that a wider drawing is associated with a higher score on this checklist. The dimensions of the EuroQoL-5D (EQ-5D) were not associated with the size of the drawings, but the EQ-5D VAS was. Specifically, the
EQ-5D VAS was negatively correlated with the width of drawing $3(R=-0.350, P<0.05)$ and the difference in head width between drawings 2 and $3(R=-0.387$, $P<0.05)$. This indicated that a wider drawing as well as a larger difference in head width between drawings 2 and 3 worse QoL as measured with the EQ-5D VAS. Finally, the total score on the AcroQoL was negatively correlated with the height of drawing $3(R=-0.693, P<0.01)$. This indicates that a taller drawing is related to worse QoL as measured with the AcroQoL. All three subscales of the AcroQoL were also negatively correlated with the height of drawing 3 (physical complaints: $R=-0.440, P<0.05$; appearance issues: $R=-0.575, P<0.01$; and personal relations issues: $R=-0.481, P<0.05$ ), indicating that a taller drawing is related to worse QoL. Furthermore, the physical complaints subscale of the AcroQoL was negatively correlated with the hand width in drawing 3 $(R=-0.433, P<0.05)$. This indicated that a wider hand was related to more physical complaints. The AcroQoL subscale appearance issues was correlated with both the difference in head width between drawings 2 and 3 $(R=0.466, P<0.05)$ and the difference in foot width between drawings 2 and $3(R=0.482, \quad P<0.05)$.

\section{Figure 2}

Examples of drawings (1, healthy state; 2 , during the active state; and 3, currently, after disease). (A1) Until I was about 40: tall, very slender (length $1.98 \mathrm{~m}$ and weight $84 \mathrm{~kg}$ ). Slender hands and fingers. Flexible and sporty. Mobile, happy, estimated to be at least 10 years younger than my actual age. (A2) Same length, heavy for me (30 kg heavier without eating extra). Hands bigger, rings do not fit anymore, deformed joints in hands. Often tired. (A3) Little change after starting somatuline injections. Weight decreased $7 \mathrm{~kg}$ with a lot of effort. Hands deforming further. (B1) Normal, slender. (B2) Big, swollen. (B3) Heavier and more swollen than 'normal', but proportions are 'normal', solid. Bones hoarser, body hoarser. (C1) Normal. (C2) Hands, feet, and nose bigger. (C3) Hands, feet, and nose shrunk somewhat. (D1) I used to have a long, slender face, small nose, and small ears (not un-pretty). My hands and feet were slender. Clothing size was 36/38. (D2) My nose and ears grew, and my face became wider. My hands and feet were also bigger and heavier. I appeared to have grown $3 \mathrm{~cm}$ after measuring. Clothing size was 42 . Wrinkles in my forehead and a weird facial expression. (D3) Not much has changed. My hands and feet are still hoarse and big. I am also getting fatter. My face is still wide. I rarely look in the mirror. I avoid pictures, because I look hideous in those. (E1) Slender young man. (E2) Puffy, tired, and

big hands. (E3) Somewhat older, slimmer, and more muscular. (F1) Seventy-one kilograms; shoe size 44; collar size 39; slender fingers (played the piano); and a lot of energy. (F2) Eighty-six kilograms; shoe size 46; collar size 43; big stiff fingers ('rheumatic'); hair on inside lower arm, on toes, and on chest; snoring; big tongue + lips: talking was difficult; and energy. (F3) Eighty-three kilograms; shoe size 46; collar size 41; big fingers; less hair; do not snore anymore; normal mouth, can speak normally again, but my teeth are completely ruined!; less energy; older skin, prone to eczema; and still look masculine! (positive). (G1) My body was tall and slender. The size of my upper body was bigger compared to my lower body. This was apparent when buying clothes. (G2) My body grew taller, wider and my face became hoarser. Big hands and feet. Deformed jaw (teeth). Bigger lower lip. (G3) After the growing process was stopped, my face looked like it used to. My lower lip stayed bigger. My hands shrank somewhat. My feet are still the same size as right after diagnosis. (H1) I was always slender/skinny. I was $1.70 \mathrm{~m}$ and weighted about $55 \mathrm{~kg}$. (H2) Slender, but very muscular. Especially considering resistance exercise: I did not do that often. (H3) Less muscular. Gained weight. I weigh almost $70 \mathrm{~kg}$. I eat little and healthy. Exercise regularly. 
Table 4 Scores on questionnaires: IPQ-R and QoL. Data are expressed as mean (s.D.).

\begin{tabular}{|c|c|}
\hline & $\begin{array}{c}\text { Patients in remission of } \\
\text { acromegaly }(n=49)\end{array}$ \\
\hline \multicolumn{2}{|l|}{ IPQ-R } \\
\hline Illness identity & $2.54(2.4)$ \\
\hline Timeline (acute/chronic) & $22.08(6.2)$ \\
\hline Timeline (cyclical) & $10.24(4.1)$ \\
\hline Consequences & $17.53(5.6)$ \\
\hline Emotional representations & $12.94(3.8)$ \\
\hline Personal control & $18.12(4.4)$ \\
\hline Treatment control & $18.00(3.5)$ \\
\hline Illness coherence & $17.44(2.7)$ \\
\hline \multicolumn{2}{|l|}{ Physical Symptom Checklist ${ }^{a}$} \\
\hline Total score & $29.83(19.7)$ \\
\hline \multicolumn{2}{|l|}{$E Q-5 D^{a}$} \\
\hline Mobility & $1.44(0.5)$ \\
\hline Self-care & $1.00(0.0)$ \\
\hline Activity & $1.54(0.6)$ \\
\hline Pain & $1.85(0.6)$ \\
\hline Anxiety & $1.41(0.7)$ \\
\hline VAS & $68.09(16.2)$ \\
\hline \multicolumn{2}{|l|}{ AcroQoL $^{a}$} \\
\hline Total score & $65.66(14.8)$ \\
\hline Physical complaints & $61.43(20.7)$ \\
\hline Appearance issues & $54.34(20.5)$ \\
\hline Personal relation issues & $78.48(13.5)$ \\
\hline
\end{tabular}

This indicates that a smaller difference in head and foot size between drawings 2 and 3 is related to a worse score on appearance issues.

\section{Discussion}

This cross-sectional explorative study demonstrates that assessment of drawings made by patients in long-term biochemical remission after acromegaly is a valuable tool. Patients' drawings reflected the perceived course of acromegaly. Specifically, the first drawing (healthy state before disease) was considered 'normal' without pain or negative emotions and without visible acromegalic symptoms. Both drawing 2 (active state of acromegaly) and drawing 3 (current state after treatment) showed a dramatic increase in size compared with drawing 1 , and a dramatic increase in the number of symptoms related to acromegaly (e.g., enlarged facial features). Furthermore, the drawings showed that patients still perceive symptoms related to acromegaly even though all patients were in long-term biochemical remission. These findings are in agreement with earlier studies that showed that the size of a drawing increases as the salience of the object to the individual increases $(8,24)$. Furthermore, these findings also show that patients perceive a change in body size and amount of symptoms during and after the disease, which do not return to the original body size before disease. This same pattern was also reflected in their psychopathology, illness perceptions, and QoL $(2,4,25,26)$. There were some interesting associations between the drawings and questionnaires measuring illness perceptions and QoL. Larger drawings were associated with more affected illness perceptions (i.e., more perceived symptoms, more cyclical timeline, more negative consequences, and stronger emotional representations). In addition, there were some associations between drawings and QoL. Larger drawings were associated with more impaired QoL as measured with the PSC, EQ-5D, and AcroQoL. As expected, a worse score on the appearance issues subscale of the disease-specific AcroQoL questionnaire seemed to be associated with larger drawings in general, and smaller differences between drawing 2 (active state) and drawing 3 (current state).

The results of the current study are in agreement with our earlier study assessing the same drawing test in patients in remission of Cushing's syndrome (11). Specifically, in this earlier study, our research group described a few associations between the drawing test and illness perceptions, but almost no associations between drawings and QoL. We concluded that drawings might be assessing a new dimension. Based on the results of this study, we can extend that conclusion although we did find more associations between the drawings and various questionnaires. Nonetheless, we still postulate that it might be useful to add the drawing test to disease-specific QoL questionnaires, such as the AcroQoL and CushingQoL $(11,22)$. Drawings add more information about the perception of the patient and can function as a starting point in providing patients with necessary information. This might be helpful in the context of patient empowerment, self-management behavior, adherence, and QoL in general (11). Furthermore, drawings will give the patient the opportunity to discuss their perception with the treating physician in a fast and easy manner. Future research might consider looking longitudinally at how patients' perceptions are changing over time and how this is related to changes in the disease state. We postulate that the drawings will be useful during every stage of acromegaly. It might be valuable to have patients draw themselves and possibly their expectations during the active state of acromegaly, using a longitudinal design. Later, after successful treatment, these 'expectation drawings' could be compared with a current drawing in order to stimulate and facilitate optimal dialog between the patient and the endocrinologist. 
This is the first study exploring the utility of the drawing test in patients in long-term remission of acromegaly. There is one earlier study that explored body image in patients with acromegaly. However, selfperception of body was assessed only by a questionnaire (i.e., the Turkish version of the Multidimensional BodySelf Relations Questionnaire), and it was unclear if patients were in (long-term) remission of acromegaly (27). Therefore, those results cannot be compared with the results of the current study.

A possible limitation of this study is the fact that only $52 \%$ of the initially invited patients participated. We cannot exclude the possibility that the most or least distressed patients were more likely to participate, which might skew the results. However, this is an explorative study aiming to investigate the utility of the drawing test in patients after long-term remission of acromegaly. We believe that the present results give a good first overview of how patients perceive acromegaly using drawings.

Another possible limitation is that we cannot be sure that drawing ability does not play a role in the interpretation of test results. However, the drawings of every participant were only compared with their own drawings (i.e., within-subject design). Furthermore, only basic characteristics of the drawings were scored (e.g., emotion: 'smiley face' or a 'sad face'). We feel that we did not incorporate any measures that heavily depended on drawing ability. A future study might want to look into the possible role of drawing ability. Furthermore, the psychological status or mood of the patient could have influenced the drawings. This has not been studied empirically, and future studies in larger cohorts might explore the possible association among mood, fatigue, or depression and the characteristics of the drawings.

The fact that the current cross-sectional study does not have a prospective design cannot be viewed as a limitation per se. We were interested in the retrospective and current perception of patients, regardless of bias in memory retrieval. The drawings represent the self-perceptions of patients before, during, and after cure of acromegaly. We were interested in the perception of the patient at one time point (after long-term remission) and the retrospective drawings reflect their current perception. In real (medical) life, patients respond to an illness, its symptoms, and its treatments by creating an image of the illness and its treatment. This image is based on information from both internal and external sources. The image patients create usually differs from the image the medical professional sketches. While we acknowledge that medical professionals may respond with amazement when researchers ask patients to report their cognitive and emotional representations of an illness, and accepting their reports at face value, theoretical and empirical works justify examining these representations. Specifically, illness representations drive coping, self-management, and, therefore, outcome (28).

In summary, the drawing test appears to be a novel and relatively simple tool to assess the perception of patients after long-term biochemical remission of acromegaly. Patients perceived a dramatic change in body size during the active state of the disease compared with the healthy state before acromegaly. Patients reported that their body did not completely return to the original proportions in the healthy state after long-term biochemical control of acromegaly. In addition, there were strong correlations between the size of the drawings and illness perceptions, with larger drawings being associated with more negative illness perceptions. The association between the drawing test and QoL was less apparent. The assessment of drawings can enable clinicians to understand patients' point of view and help them discuss the symptoms and consequences patients draw as well as the emotions portrayed. Furthermore, drawings might enable patients to talk about treatment and how remission affects the body.

\section{Declaration of interest}

The authors declare that there is no conflict of interest that could be perceived as prejudicing the impartiality of the research reported.

\section{Funding}

This research did not receive any specific grant from any funding agency in the public, commercial or not-for-profit sector.

\section{References}

1 Biermasz NR, Pereira AM, Smit JW, Romijn JA \& Roelfsema F. Morbidity after long-term remission for acromegaly: persisting joint-related complaints cause reduced quality of life. Journal of Clinical Endocrinology and Metabolism 200590 2731-2739. (doi:10.1210/jc.2004-2297)

2 Biermasz NR, van Thiel SW, Pereira AM, Hoftijzer HC, van Hemert AM, Smit JW, Romijn JA \& Roelfsema F. Decreased quality of life in patients with acromegaly despite long-term cure of growth hormone excess. Journal of Clinical Endocrinology and Metabolism 200489 5369-5376. (doi:10.1210/jc.2004-0669)

3 Tiemensma J, Kaptein AA, Pereira AM, Smit JWA, Romijn JA \& Biermasz NR. Coping strategies in patients after treatment for functioning or nonfunctioning pituitary adenomas. Journal of Clinical Endocrinology and Metabolism 201196 964-971. (doi:10.1210/ jc.2010-2490)

4 Tiemensma J, Kaptein AA, Pereira AM, Smit JWA, Romijn JA \& Biermasz NR. Affected illness perceptions and the association with 
impaired quality of life in patients with long-term remission of acromegaly. Journal of Clinical Endocrinology and Metabolism 201196 3550-3558. (doi:10.1210/jc.2011-1645)

5 Leventhal H, Meyer D \& Nerenz D. The common sense representation of illness danger. In Contributions to Medical Psychology, pp 7-30. Ed. S Rachman, New York, NY: Pergamon, 1980.

6 McAndrew LM, Musumeci-Szabó TJ, Mora PA, Vileikyte L, Burns E, Halm EA, Leventhal EA \& Leventhal H. Using the common sense model to design interventions for the prevention and management of chronic illness threats: from description to process. British Journal of Health Psychology 200813 195-204. (doi:10.1348/135910708X295604)

7 Petrie KJ, Cameron LD, Ellis CJ, Buick D \& Weinman J. Changing illness perceptions after myocardial infarction: an early intervention randomized controlled trial. Psychosomatic Medicine 200264 580-586. (doi:10.1097/00006842-200207000-00007)

8 Broadbent E, Ellis CJ, Gamble G \& Petrie KJ. Changes in patient drawings of the heart identify slow recovery after myocardial infarction. Psychosomatic Medicine 200668 910-913. (doi:10.1097/01. psy.0000242121.02571.10)

9 Reynolds L, Broadbent E, Ellis CJ, Gamble G \& Petrie KJ. Patients' drawings illustrate psychological and functional status in heart failure. Journal of Psychosomatic Research 200763 525-532. (doi:10.1016/ j.jpsychores.2007.03.007)

10 Broadbent E, Petrie KJ, Ellis CJ, Ying J \& Gamble G. A picture of health myocardial infarction patients' drawings of their hearts and subsequent disability: a longitudinal study. Journal of Psychosomatic Research 2004 57 583-587. (doi:10.1016/j.jpsychores.2004.03.014)

11 Tiemensma J, Daskalakis NP, van der Veen EM, Ramondt S, Richardson SK, Broadbent E, Romijn JA, Pereira AM, Biermasz NR \& Kaptein AA. Drawings reflect a new dimension of the psychological impact of long-term remission of Cushing's syndrome. Journal of Clinical Endocrinology and Metabolism 201297 3123-3131. (doi:10.1210/ jc.2012-1235)

12 Broadbent E, Niederhoffer K, Hague T, Corter A \& Reynolds L. Headache sufferers' drawings reflect distress, disability and illness perceptions. Journal of Psychosomatic Research 200966 465-470. (doi:10.1016/ j.jpsychores.2008.09.006)

13 Van Stralen G, van Stralen-Ruijten LL, Spaargaren CF, Broadbent E, Kaptein AA \& Scherjon SA. Good quality of life after emergency embolisation in postpartum haemorrhage. Journal of Psychosomatic Obstetrics and Gynaecology 201031 285-288. (doi:10.3109/0167482X. 2010.528092)

14 Kaptein AA, Zandstra T, Scharloo M, Vogel JJ, Broadbent E, Hughes BM, Godefroy WP \& van der Mey AG. "A time bomb ticking in my head": drawings of inner ears by patients with vestibular schwannoma. Clinical Otolaryngology 201136 183-184. (doi:10.1111/j.1749-4486.2011. 02264.x)

15 Daleboudt GM, Broadbent E, Berger SP \& Kaptein AA. Illness perceptions in patients with systemic lupus erythematosus and proliferative lupus nephritis. Lupus 201120 290-298. (doi:10.1177/ 0961203310385552)

16 Biermasz NR, Dekker FW, Pereira AM, van Thiel SW, Schutte PJ, van Dulken H, Romijn JA \& Roelfsema F. Determinants of survival in treated acromegaly in a single center: predictive value of serial insulin-like growth factor I measurements. Journal of Clinical Endocrinology and Metabolism 200489 2789-2796. (doi:10.1210/ jc.2003-032041)

17 Van der Klaauw AA, Bax JJ, Roelfsema F, Stokkel MP, Bleeker GB, Biermasz NR, Smit JW, Romijn JW \& Pereira AM. Limited effects of growth hormone replacement in patients with GH deficiency during long-term cure of acromegaly. Pituitary 200912 339-346. (doi:10.1007/ s11102-009-0186-y)

18 Moss-Morris R, Weinman J, Petrie K, Horne R, Cameron L \& Buick D. The Revised Illness Perception Questionnaire (IPQ-R). Psychology and Health 200217 1-16. (doi:10.1080/08870440290001494)

19 American Psychiatric Association. Diagnostic and Statistical Manual of Mental Disorders, Third Edition. Washington D.C.: American Psychiatric Association, 1980.

20 De Waal MW, Arnold IA, Spinhoven P, Eekhof JA \& van Hemert AM. The reporting of specific physical symptoms for mental distress in general practice. Journal of Psychosomatic Research 200559 89-95. (doi:10.1016/j.jpsychores.2005.02.011)

21 The EuroQol Group. EuroQol - a new facility for the measurement of health-related quality of life. The EuroQol Group. Health Policy 199016 199-208. (doi:10.1016/0168-8510(90)90421-9)

22 Webb SM, Prieto L, Badia X, Albareda M, Catala M, Gaztambide S, Lucas T, Paramo C, Pico A, Lucas A et al. Acromegaly Quality of Life Questionnaire (ACROQOL) a new health-related quality of life questionnaire for patients with acromegaly: development and psychometric properties. Clinical Endocrinology 200257 251-258. (doi:10.1046/j.1365-2265.2002.01597.x)

23 Rasband WS. ImageJ (version 1.42Q), U S National Institutes of Health, Bethesda, MD, USA (available at: http://rsb.info.nih.gov/ij/), cited November 2014.

24 Craddick R. Height of Christmas tree drawings as a function of time. Perceptual and Motor Skills 196317 335-339. (doi:10.2466/pms.1963.17. 2.335)

25 Tiemensma J, Biermasz NR, van der Mast RC, Wassenaar MJ, Middelkoop HA, Pereira AM \& Romijn JA. Increased psychopathology and maladaptive personality traits, but normal cognitive functioning, in patients after long-term cure of acromegaly. Journal of Clinical Endocrinology and Metabolism 201095 E392-E402. (doi:10.1210/ jc.2010-1253)

26 Van der Klaauw AA, Kars M, Biermasz NR, Roelfsema F, Dekkers OM, Corssmit EP, van Aken MO, Havekes B, Pereira AM, Pijl H et al. Diseasespecific impairments in quality of life during long-term follow-up of patients with different pituitary adenomas. Clinical Endocrinology 2008 69 775-784. (doi:10.1111/j.1365-2265.2008.03288.x)

27 Hatipoglu E, Topsakal N, Atilgan OE, Alcalar N, Camliguney AF, Niyazoglu M, Cotuk HB \& Kadioglu P. Impact of exercise on quality of life and body-self perception of patients with acromegaly. Pituitary 2014 17 38-43. (doi:10.1007/s11102-013-0463-7)

28 Leventhal H, Brissette I \& Leventhal EA. The common-sense model of self-regulation of health and illness. In The Self-Regulation of Health and Illness Behaviour, pp 42-65. Eds LD Cameron \& H Leventhal, London: Routledge, 2003.

Received 17 November 2014

Revised version received 30 January 2015

Accepted 20 February 2015 